\title{
Synthesis of Thermally Stable Carboxymethyl Cellulose/Metal Biodegradable Nanocomposites for Potential Biological Applications
}

\author{
Nadagouda N. Mallikarjuna and Rajender S. Varma* \\ Sustainable Technology Division, US Environmental Protection Agency, National Risk \\ Management Research Laboratory, 26 West Martin Luther King Drive, MS 443, \\ Cincinnati, OH 45268, USA.
}

Tel: (513) 487-2701; Fax: (513) 569-7677; E-mail: varma.rajender@epa.gov

\section{Caption to Figures}

Figure S1. Photographic image of carboxymethyl cellulose nanocomposite with (a) $\mathrm{Cu}$, (b) In, (c) Fe and (d) Ag.

Figure S2. Photographic image of CMC reduced $\mathrm{Au}, \mathrm{Pt}$ and $\mathrm{Pd}$ (from left to right) synthesized using MW at $100{ }^{0} \mathrm{C}$ for 5 minutes.

Figure S3. SEM image of CMC nanocomposite with (a) Cu, (b) Fe, (c) In and (d) Ag.

Figure S4. TEM image of carboxymethyl cellulose nanocomposite with $\mathrm{Cu}$.

Figure S5. TEM image of carboxymethyl cellulose nanocomposite with Pd.

Figure S6. TEM image of carboxymethyl cellulose reduced Pt nanostructures.

Figure S7. Selected area diffraction pattern (SAED)of carboxymethyl cellulose reduced Pt nanostructures. 


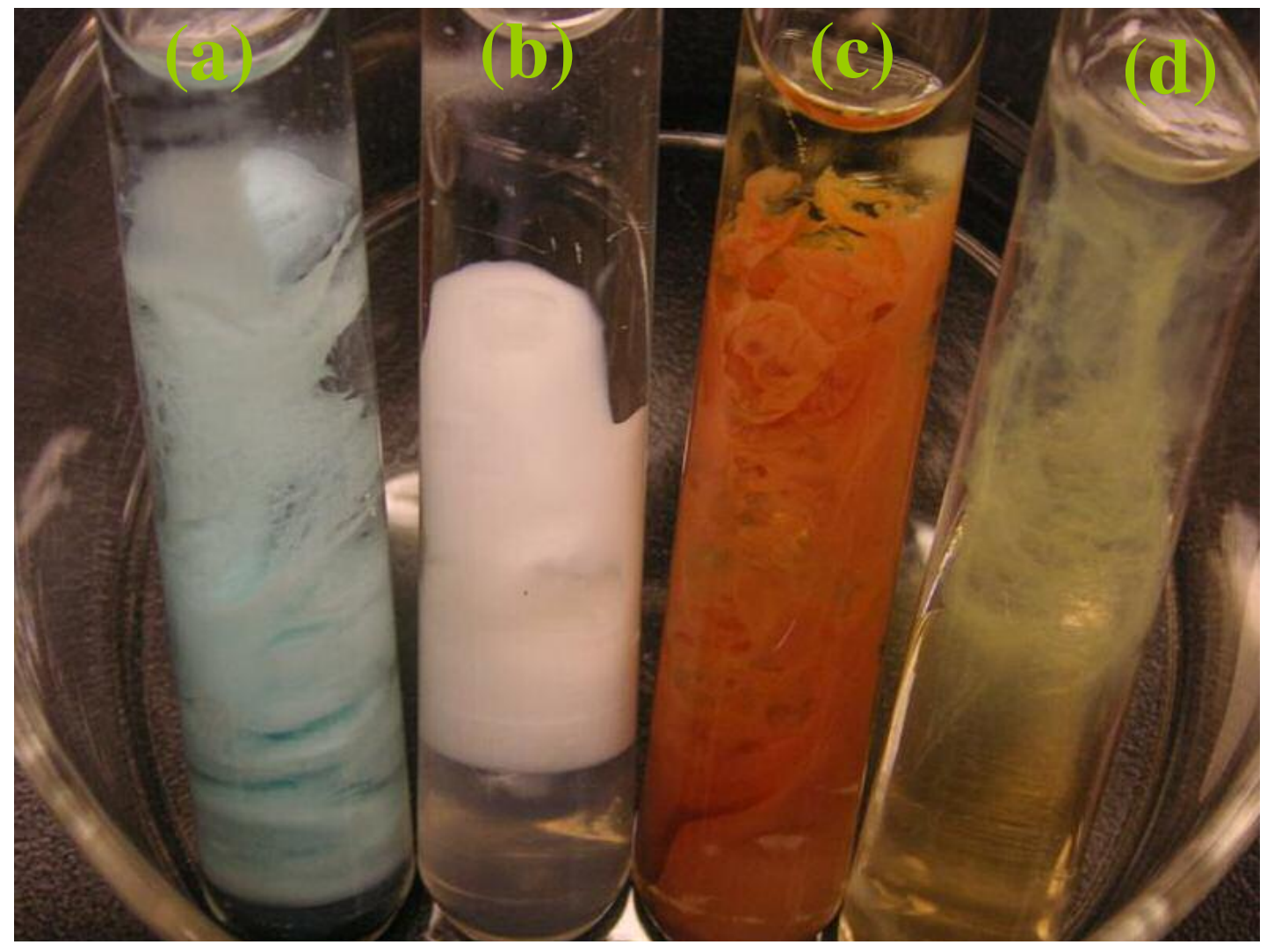

Figure S1. Photographic image of carboxymethyl cellulose nanocomposite with (a) $\mathrm{Cu}$, (b) In, (c) Fe and (d) Ag. 


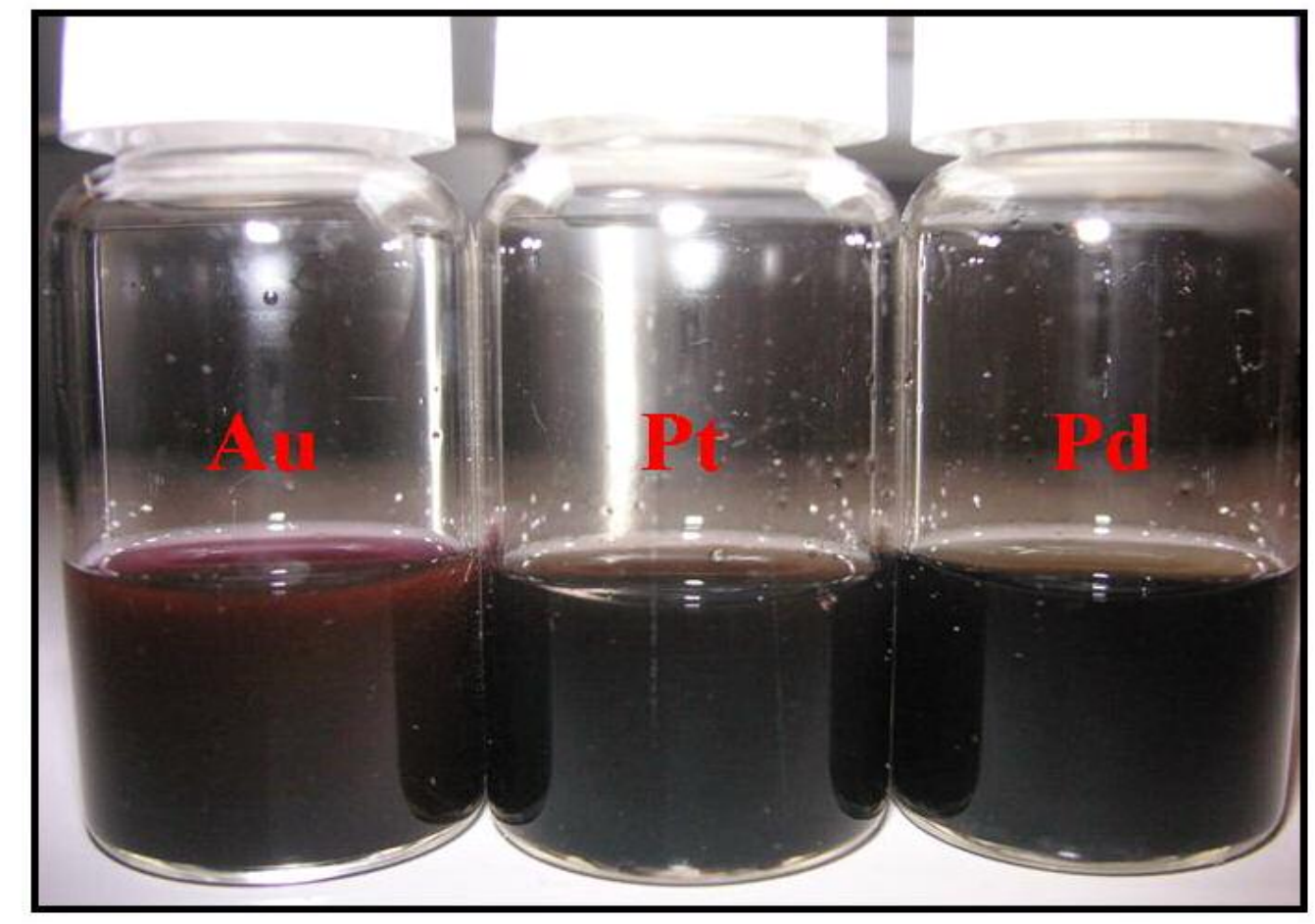

Figure S2. Photographic image of $\mathrm{CMC}$ reduced $\mathrm{Au}, \mathrm{Pt}$ and $\mathrm{Pd}$ (from left to right) synthesized using MW at $100{ }^{\circ} \mathrm{C}$ for 5 minutes. 

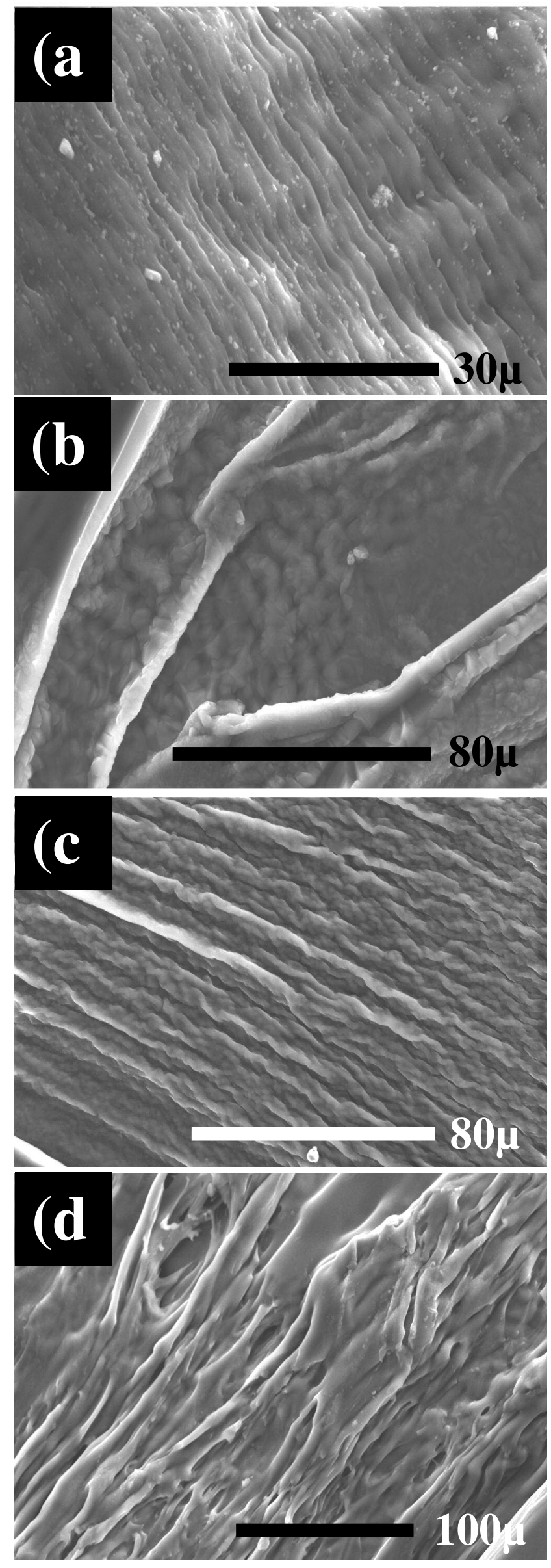
Figure S3. SEM image of CMC nanocomposites with (a) $\mathrm{Cu}$, (b) $\mathrm{Fe}$, (c) In and (d) Ag.

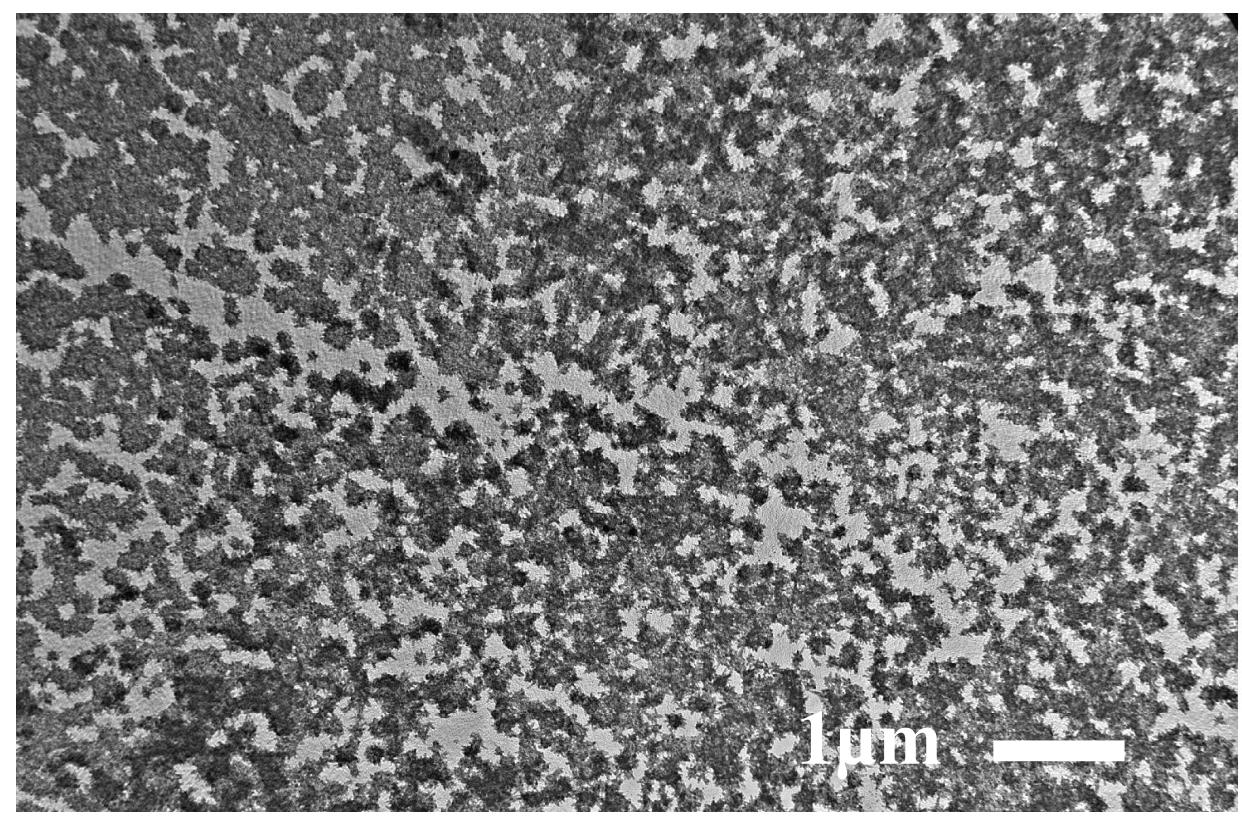

Figure S4. TEM image of carboxymethyl cellulose nanocomposite with $\mathrm{Cu}$.

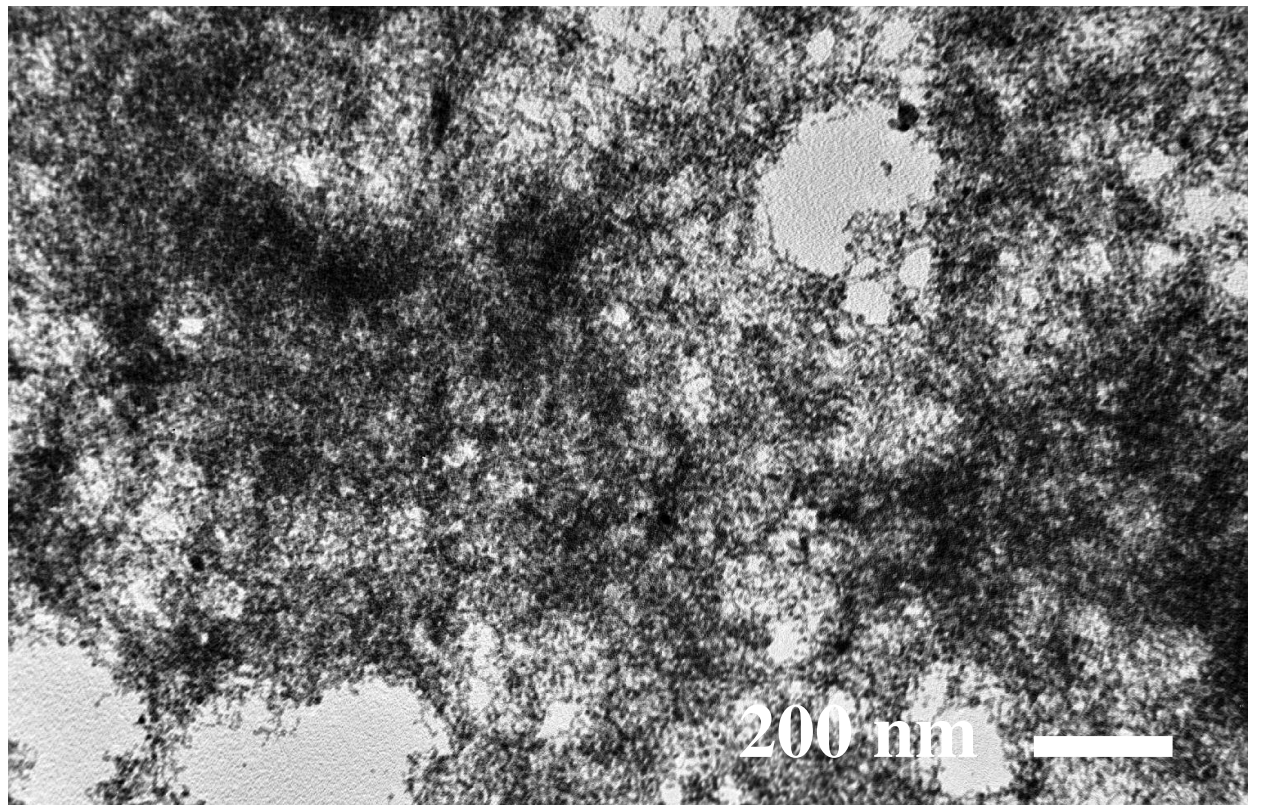

Figure S5. TEM image of carboxymethyl cellulose reduced Pd nanostructures. 


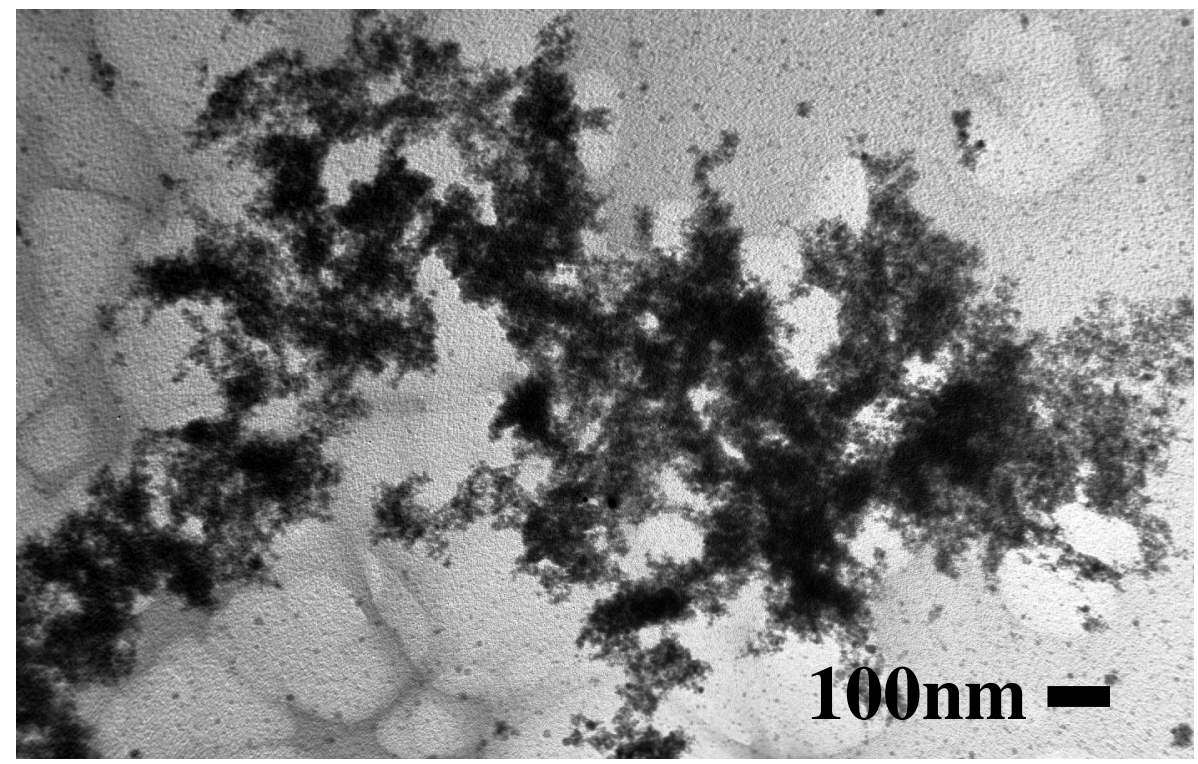

Figure S6. TEM image of carboxymethyl cellulose reduced Pt nanostructures.

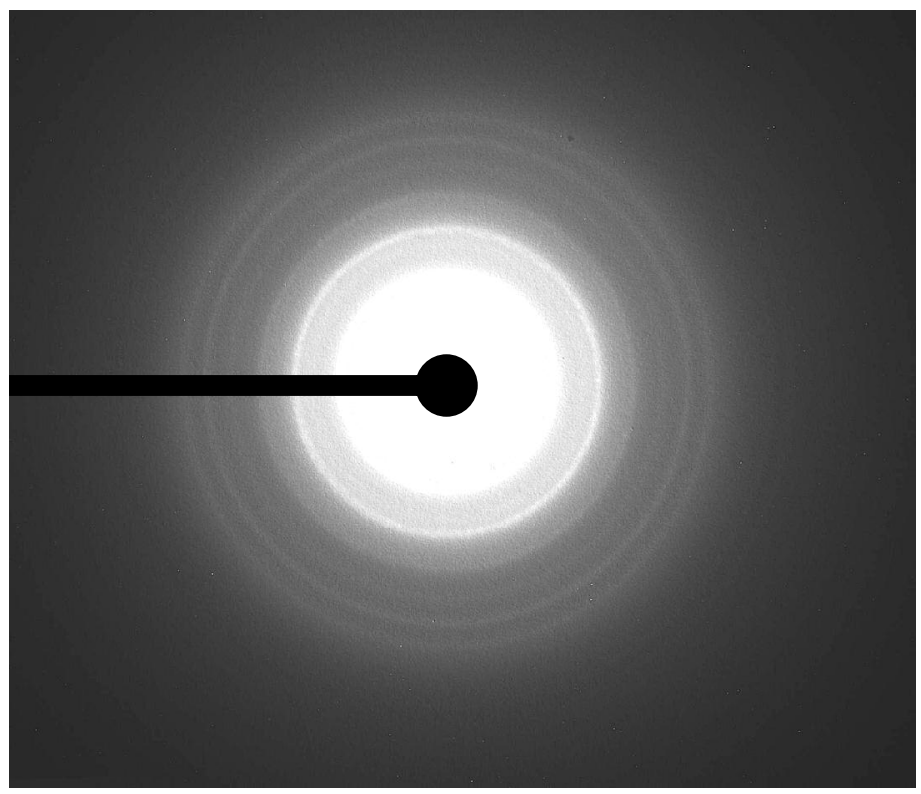

Figure S7. Selected area diffraction pattern (SAED) of carboxymethyl cellulose reduced Pt nanostructures. 